\title{
Aplicações de elementos da teoria das catástrofes ao estudo da (re) produção do espaço urbano: parte 1 - como Henri Lefebvre trouxe René Thom para o debate
}

\section{Applications of elements of catastrophe theory to the study of the (re) production of urban space: part 1 - as Henri Lefebvre brought René Thom to the debate}

\author{
James Amorim Araújo $₫$ (iD \\ Departamento de Ciências Humanas, Campus V, Universidade do Estado da Bahia, Santo \\ Antônio de Jesus, Bahia, Brasil \\ E-mail: jaraujo@uneb.br
}

Recebido (Received): 30/04/2019

Aceito (Accepted):16/04/2020

\begin{abstract}
Resumo: Este artigo trata a aplicação de conceitos e noções oriundos da Teoria das Catástrofes à abordagem da produção do espaço urbano na Geografia. Neste sentido, objetiva reinterpretar a (re)produção do espaço como um fenômeno de caráter morfológico passível de ser representado pelas noções de morfogênese e morfologia hierárquica estratificada. Além disso, propõe funções baseadas no valor como medidas da escala de (re)produção morfológica. A base teórica deste artigo contempla o teorema da morfogênese de René Thom, assim como a contribuição fundamental de Henri Lefebvre sobre o papel do Estado na "normalização" das crises do capitalismo no século XX. Portanto, entende-se que a discussão aqui apresentada é uma contribuição ao arsenal teórico da Geografia, em particular, de sua abordagem da produção do espaço urbano.
\end{abstract}

Palavras-chave: Morfogênese; Morfologia Hierárquica Estratificada; (Re)Produção Morfológica.

Abstract: This article deals with the application of concepts and concepts of Disaster Theory to the approach to the production of urban space in Geography. In this sense, it aims to reinterpret (re) production of space as a phenomenon of morphological character that can be represented by the notions of morphogenesis and stratified hierarchical morphology. In addition, it proposes functions based on value as measures of morphological (re) production scale. The theoretical basis of this article contemplates the theorem of the morphogenesis of René Thom, as well as the fundamental contribution of Henri Lefebvre on the role of the State in the "normalization" of the crises of capitalism in the twentieth century. Therefore, it is understood that the discussion presented here is a contribution to the theoretical arsenal of Geography, in particular, its approach to the production of urban space.

Keywords: Morphogenesis; Stratified Hierarchical Morphology; (Re)Production Morphologic.

\section{Apresentação}

Este é um artigo eminentemente teórico. Ele faz parte de conjunto de produções advindas do projeto de pesquisa em nível de pós-doutoramento. A idealização do projeto surgiu quando eu ainda realizava o doutorado, de 2006 a 2010. À época, a descoberta da Teoria das Catástrofes a partir da obra de Lefebvre "De l'État, tomo IV (1978)", fez-me perceber o seu possível de emprego na abordagem da produção do espaço. Efetivamente, ainda na tese de doutoramento, empreguei sistematicamente a noção de morfologia hierárquica estratificada na intepretação da produção espacial de Salvador/BA, através de gráficos e representações que aproximavam a noção dos eventos históricos relativos à cidade, mas faltava ainda o embasamento teórico 
que fizesse a correlação dos eventos históricos à noção de morfologia proposta por Lefebvre. Portanto, foi esta busca que motivou a realização do pós-doutoramento e o que dele resultou.

A Teoria das Catástrofes é um teorema criado pelo matemático francês René Thom na década de 1950 e visa, em linhas gerais, demonstrar a morfogênese de uma dada morfologia. A ideia de base desta teoria busca demonstrar a superação morfológica por outra mais complexa, por isso, seu foco está na crise/ruptura e não necessariamente na continuidade. Ainda segundo Thom, o que interessa realmente é entender como ocorre a degeneração de uma morfologia através de seus pontos críticos, portanto, este é o objeto central desta teoria. De acordo com Marsault (1998), a noção de base da Teoria das Catástrofes é a de ponto crítico ou ruptura de uma função regular.

Pelo fato de a teoria problematizar em termos genéricos uma sucessão morfológica, ela apresenta um potencial emprego na interpretação da produção espacial porque o espaço social é também uma materialidade. Argumentamos em favor desta discussão com o intuito de contribuir com o avanço de teorização na Geografia. Afinal, sabemos que o espaço é produzido, usado, apropriado e substituído, mas não sabemos demonstrar isto em termos de uma grandeza escalar. Bem, tal empresa não é um caminho fácil porque a reflexão geográfica passa ao largo de tudo que se refere a cálculos ou parametrizações, provavelmente, por causa da longa tradição descritiva desta ciência. No entanto, o que se propõe ou que se objetiva neste artigo é refletir sobre a incorporação de noções oriundas do referido teorema que contribuam na demonstração do processo de (re)produção espacial a partir da proposição de medidas que dimensionem a morfologia espacial. Por isto, entendemos ser esta uma contribuição possível a ser feita à Geografia.

Além desta apresentação, este artigo está dividido nas seguintes partes: a introdução, na qual apresentamos a problemática de pesquisa que norteou nossas reflexões teóricas, em seguida, a discussão teórica empreendida e, por último, nossas considerações parciais.

\section{Introdução}

A Geografia, apesar de sua longa tradição que remonta desde a antiguidade clássica Grega, nunca conseguiu superar uma episteme pautada na relação (função) de cartesiana que representa o espaço nos sentidos (norte-sul) e (leste-oeste). Esta representação do espaço, apesar de necessária, porque nos permite identificar a disposição dos fenômenos na superfície terrestre, não é suficiente para a abordagem da produção do espaço, porque não revela nem as acumulações morfológicas e suas rupturas nem a dimensão abstrata da produção. Muito embora saibamos que se faz necessário a incorporação de medidas de produção, isto é praticamente impossível dentro dos padrões epistemológicos recorrentes na Geografia.

A ascensão da abordagem da produção do espaço, em sucessão à da organização, constituiu um campo epistemológico de base materialista dialética na Geografia pós $2^{\mathrm{a}}$ Guerra Mundial. Este campo incorporou inúmeras reflexões e noções oriundas do pensamento marxiano antes ausentes como, por exemplo, produção, processo, forma, função, estrutura, nível, dentre muitas outras. Isto permitiu a uma interpretação teórica sobre a dimensão abstrata da produção a partir das relações sociais, contudo, certas demonstrações de base empírica (fenomênica) ainda carecem de elementos tangíveis, fato que limita o horizonte de análise crítica da (re)produção espacial.

Esta constatação coloca um problema teórico, mas também prático para esta abordagem, isto é, de nada adianta afirmar que o espaço é (re)produzido se não há como demonstrar isto em parâmetros ou variáveis medíveis. Obviamente, a Geografia não é uma "física espacial", logo, a possibilidade de parametrizações é bastante limitada, mas como o próprio René Thom afirma "pode-se proceder por classificações de caractere qualitativo ou topológico(...) estas classificações poderão evidentemente utilizar, a cada vez, igualmente algoritmos matemáticos e não apenas taxonomias de caractere conceitual." (1983, p. 93). Contudo, como fazer isto?

Uma possível solução para o que sugere Thom seria a proposição de funções provenientes de relações socioespaciais de (re)produção do espaço. Contudo, tal solução preconizaria a introdução de três aplicações da matemática à Geografia. Primeiramente teríamos uma incorporação topológica para descrever momentos sucessivos de um conjunto morfológico, uma vez que para a Teoria das Catástrofes o importante é destacar a morfogênese. A partir dessa aplicação topológica, duas novas aplicações fariam o complemento - uma algébrica (funções) e, finalmente, uma geométrica. Infelizmente, para o propósito deste trabalho, não teremos condição de abranger todas essas aplicações, logo, nos concentraremos nas aplicações algébricas para perseguir uma caracterização da morfologia espacial.

Muito embora aparentemente existam aplicações matemáticas para a produção do espaço, seu uso na Geografia está longe de ser simples. Afinal o cerne da aproximação está tanto em "captar" o movimento de 
(re)produção espacial, o que engloba as continuidades e as descontinuidades, quanto fazer uso de noções que representem este processo. Então, como incorporar os elementos da Teoria das Catástrofes à produção do espaço? Especificamente, como tratar da superação/sobreposição de morfologias espaciais, especificadamente urbanas, a partir deste teorema e de um exemplo concreto? Este é o nosso desafio.

Para encaminhar uma solução, propomos três hipóteses teóricas de trabalho: primeira - a (re)produção do espaço é um processo marcado por descontinuidades e sobreposições de formas, funções e estruturas submetidas à lógica de reprodução do capital ao longo do século XX, o que implica no uso da noção de morfologia hierárquica estratificada, tal como proposta por Lefebvre (1978); segunda - o mecanismo de base que provoca as descontinuidades e morfogêneses é, com efeito, o acúmulo diferencial de capital ao espaço; e, terceira - para todo valor do espaço há um corresponde dialético, ou seja, o seu antivalor.

Então reiteramos que há uma correlação evidente entre o acúmulo (acreção) diferencial de morfologias e o processo de acumulação de capital ao espaço, o qual pode ser parametrizada (modelizada) ao utilizarmos a noção fundamental da Teoria das Catástrofes, ou seja, a morfogênese, mas sob a releitura crítica proposta por Lefebvre.

Como se trata de uma reflexão teórica, nosso encaminhamento parte do plano da abstração das relações de produção do espaço enquanto produto para a sua efetivação enquanto meio de consumo/mercadoria. Dito isto, traremos na seção seguinte a discussão teórica desta pesquisa.

\section{A Teoria das catástrofes e a produção e valorização do espaço}

Um dos mais intrigantes e profícuos campos de expansão teórica no estudo da (re)produção do espaço, na atualidade, refere-se à introdução da noção de morfogênese aos estudos de morfologias. Esta noção ajudaria a revelar as rupturas, descontinuidades, de uma dada morfologia e a imposição de outra mais complexa.

O modo pelo qual estas noções se tornaram significantes para o conhecimento científico, em especial, para as ciências humanas é bastante inusitado. Diferentemente do que se imagina, foi pela crítica aos conhecimentos até então acumulados no seio do próprio marxismo, assim como ao estruturalismo que Henri Lefebvre se aproximou da matemática das catástrofes de René Thom.

Uma primeira "entrada" empreendida por Lefebvre (2009) por meio da noção de morfologia hierárquica estratificada adveio do conteúdo do termo "crise" forjado no seio do próprio marxismo. De uma maneira geral, o autor diz que "poderíamos supor que a 'crise' resulta do fato de que os elementos da vida social recusaram os laços que os uniam" (2009, p. 140). Por outro lado, de acordo com o próprio pensamento do filósofo "o pensamento dito marxista não contribuiu até agora para o conhecimento das situações concretas", mas "ele também fez avançar, desde Marx, o conceito de transição, ou seja, um evento entre "continuidades" (2009, p. 140).

Por que o pensamento marxista oscilou entre um extremo e outro, sendo que a realidade não validou nem uma interpretação nem outra? De acordo com Lefebvre "porque ele não analisava o Estado, sua capacidade crescente de intervenção e de gestão, estimulada e não abatida pelas crises e pelas guerras." (2009, p. 141). Portanto, a análise marxiana "desde há muito não compreendeu a generalização e a normalização da crise no mundo atual: o estado crítico com suas implicações não explicitadas." (2009, p. 141).

A relação entre espaço e Estado é possível de ser apreendida pelo estudo das "unidades discretas de formas definidas" (OSEKI, 1996, p. 115), tais unidades constituem conjuntos ou morfologias em níveis inter-relacionados e o conceito de morfologia hierárquica estratificada "desencadeia aquele de "espaço de catástrofe" (LEFEBVRE, 1978, p. 256). A articulação entre os níveis também pressupõe o seu contrário, a ruptura, por isto Lefebvre (1971, p. 105) propôs a noção de desnivelamento. As chamadas "crises" clássicas tomam seu lugar na Teoria das Catástrofes como um mecanismo sintomático de um evento, a morfogênese. Esta abala as condições de reprodução estável de uma morfologia e, com efeito, conduz a sua superação. Portanto, não se trata de uma crise tal como previa Rosa de Luxemburgo (1899) no sentido de um fim, em que a acumulação capitalista cessaria. Não se trata disto, mas antes da desestabilização de uma morfologia e sua sucessão por outra na qual a reprodução capitalista se atualiza e se complexifica.

Na Geografia, o termo morfologia é polissêmico. Isto se deve ao fato de haver inúmeras definições sobre o que é espaço também. Por outro lado, respeitadas as variadas definições, a abordagem aqui adotada é baseada no materialismo geográfico, portanto, os autores desta abordagem que discutem morfologia a entendem como um conjunto de unidades discretas do espaço destinadas à reprodução das relações sociais (produção, circulação, distribuição e consumo). Com efeito, autores como Corrêa (2001) e Santos (1997), dentre outros, entendem morfologia como sendo uma configuração territorial. 
Santos (1997), por exemplo, define a configuração territorial como o conjunto dos objetos implantados na superfície terrestre e que formam um "sistema de objetos". É bem verdade que Santos alerta para o fato que a configuração territorial não é espaço, uma vez que se faz necessário a sociedade operando neste "sistema de objetos". Apesar de termos ressalvas à equiparação de espaço a sistema, pois a nosso ver reduz a complexidade da dimensão espacial, reconhecemos que essa compreensão de Santos sobre o espaço é resultante da contribuição fundamental de Henri Lefebvre (A produção do espaço de 1974) com a elaboração do conceito de espaço social.

Antes de prosseguirmos na exposição é preciso fazer uma ressalva. A introdução da noção de morfologia hierárquica estratificada implica pensar em uma acumulação histórica de morfologias. Esta acumulação ocorre em camadas e, à medida que se acumulam, tornam a morfologia mais complexa. Ora, por que uma morfologia hierárquica estratificada vai se tornando mais complexa? Porque responde aos processos sociais da totalidade social marcados, na atualidade, pela troca mercantil, pela equivalência e propriedade privada, fatos que reiteram processos tidos como acumulativos. Além deste acúmulo de camadas, é importante observar que este processo ocorre seguindo uma lógica (uma sócio-lógica) de estratificação.

Aqui se abre a uma profícua reflexão entre a abordagem da (re)produção do espaço e sua relação com a Teoria das Catástrofes, a respeito do que se entende de estrutura social, a dimensão institucional (o Estado), a materialidade do processo social e a definição teórica de Thom sobre campo morfogenético.

A estratificação é um processo interno à totalidade social de superação das comunidades e da divisão sexual do trabalho por sociedades complexas, nas quais a divisão social do trabalho se desdobra. Este processo de complexificação social tende à instauração de distinções de natureza econômica (classes/frações de classe), social (status/estamentos) e política (poder/conflitos) (STAVENHAGEN, 1980, p. 284). Contudo, uma ponderação é absolutamente necessária à compreensão de estratificação morfológica, pois, se apenas analisarmos a estratificação sob uma perspectiva estrutural, deixamos de considerar as tensões e movimentos internos. Dito em outras palavras, a estratificação é um processo dinâmico porque histórico.

Além do processo de estratificação oriundo das relações sociais, há também a insurgência da Estado no seio da formação social com papel essencialmente regulatório para o capital. O Estado reitera as divisões de classes e, portanto, o processo de estratificação ao equalizar os desiguais, por meio de uma homogeneização induzida e reforçada (KOSMINSKI \& ANDRADE, 1996, p. 67). Com efeito, tal processo de estratificação se revela na morfologia e a conduz em sentido reprodutivo. Este sentido e direcionamento teleológico da reprodução morfológica é denominado por René Thom de "campo morfogenético".

Muito embora o "campo morfogenético" seja fruto de um projeto (social), isto não significa ser possível igualar uma morfologia hierárquica estratificada a condição de um sistema. Insistimos nesta afirmação por entendermos que um sistema é uma leitura simplificadora da totalidade social em seu movimento de formação. Um sistema, mesmo tido como complexo e aberto, abstrai tanto a temporalidade (processo) quanto as contradições de uma morfologia ao hipostasiar seu arranjo ou estrutura. Ora, morfologias hierarquizadas e estruturadas são marcadas por continuidades e descontinuidades em seu processo de reprodução, porque são fruto das relações sociais definidas enquanto formação social, mas que se realizam até ao rés do chão. Se ao nível teórico-analítico, a continuidade é relativamente bem estudada, o mesmo não acontece com a descontinuidade morfológica, logo, resta-nos avançar na discussão teórico-metodológica deste processo.

De uma maneira geral, as ciências sociais tratam a noção de descontinuidade ou desnivelamento por meio de representações de crises. Apesar de sua ampla disseminação no seio das ciências, o próprio Lefebvre nos alertava para tal incorreção, pois, "em vez de dizer 'crise', seria necessário dizer estado crítico do mundo moderno em geral, do modo de produção estatista em particular." (2009, p. 145). Seria preciso, então, superar a visão clássica de crise, logo, é uma maneira diferente de ver a realidade e, consequentemente, o que nos interessa - a (re)produção de uma morfologia espacial.

Para René Thom (1989, p. 14) um conjunto morfológico é estável estruturalmente se qualquer forma $b$ é suficientemente próxima a $a$. Como é possível entender e descrever um conjunto morfológico? A derivação exige cuidado aqui. Não podemos começar a partir da aparência das coisas. Temos que partir de seu conteúdo de determinação. Neste sentido, as relações sociais em seu nível mais abstrato possível e, ao mesmo tempo, o mais concreto, isto é, a troca de valores - a equivalência.

A crise ou um fenômeno catastrófico ocorre com a quebra de simetria e comutatividade das unidades discretas entre conjuntos. A causa da quebra de simetria e, portanto, da relação de equivalência é a introdução no campo morfológico de um outro atrator com força suficiente para redirecionar a reprodução das formas. Dizemos então que um atrator se trata de uma força produzida pelo processo social cuja ação redefine o sentido e os tipos morfológicos reprodutíveis. Com efeito, trata-se de uma reestruturação e, como 
tal, implica em alterações em todo o conjunto morfológico, desde os níveis mais abstratos quanto os mais concretos.

Ora, se em um campo morfológico um segundo atrator é introduzido diremos que estamos diante de um conflito em um sentido dialético. Este conflito pode indicar uma superação de reprodução das formas anteriores por formas ajustadas à estrutura social, um processo de acreção ou o seu contrário. Dito em outras palavras, um segundo atrator gera uma descontinuidade.

Dessa maneira, alcançamos a condição de definir que a descontinuidade é, na realidade, uma condição indicadora de um processo de morfogênese, ou seja, um processo criador e destruidor de formas ao mesmo tempo. Toda morfogênese advém de um conflito, isto é, de uma luta entre dois ou vários atratores. Segundo Thom (1993), a catástrofe é uma manobra de sobrevivência de uma morfologia colocada na condição de sair de sua característica normal, ou seja, simétrica e transitiva.

Então, como a morfogênese ocorre? Em sua resposta às críticas feitas ao seu primeiro livro de 1972, Thom (1980) detalha que o trajeto do processo de morfogênese pode conduzir, a depender do tipo de conflito estabelecido entre os atratores, há dois tipos de catástrofes - as do tipo conflito e as do tipo bifurcação. As primeiras "determinam o tipo morfológico das superfícies de ondas de choque que separam os diferentes domínios onde reinam atratores em competição" (p. 91), mas não existe perda de potência de um deles. Por outro lado, as catástrofes de bifurcação determinam tipos morfológicos onde "o conflito entre atratores conduz ao menos um deles a deixar de ser estruturalmente estável" (p. 92) Não podemos deixar de observar que uma catástrofe de bifurcação se assemelha, em muito, ao entendimento materialista (Hegel-Marx) da superação do tipo Aufheben, isto é, superação com conservação. Ver para isto "O Fim da História" de Lefebvre de 1971.

Então o espaço de catástrofe criado pela morfogênese conduz a uma superação da morfologia espacial anterior. Este processo se realiza abstratamente e também no concreto. René Thom (1989) propôs uma modelização dos tipos primários de catástrofes e, com efeito, no caso específico da morfologia hierárquica estratificada, seu comportamento estaria próximo a um tipo particular de catástrofe chamado de fronce ou cúspide. Segundo Lopes (2012) a catástrofe tipo cúspide é a mais adequada para pensarmos a morfogênese urbana porque além de englobar a relação das dimensões espaço/tempo por meio de uma função de quarto grau (três dimensões espaciais - xyz, e uma dimensão temporal - t). De acordo com Thom (1980, p. 92) a função que representa a singularidade deste tipo de catástrofe é $Y=x 4 / 4$, no entanto, para efetivarmos tal aplicação algébrica precisamos levantar justamente a variável de $\mathrm{x}$ em três dimensões espaciais e uma de tempo (que é uma variante do espaço). Aqui retomamos ao velho dilema epistemológico da Geografia porque, basicamente, trabalhamos apenas com duas dimensões espaciais.

A catástrofe tipo cúspide modeliza a morfologia por meio do par (continuidade: engendrar (reprodução)/descontinuidade: ruptura). Dessa maneira, são representações abstratas de movimentos reiteradamente destacados nos estudos urbanos, mas que, no entanto, não são traduzidos em uma formulação matemática porque não há teorização neste sentido.

Ainda sobre a catástrofe cúspide, Domingues (2004) argumenta que sua morfogênese se compõe por uma sequência de três (3) tipos de eventos/momentos quanti/qualitativamente distintos: o ponto de ruptura, depois o de dobra e, finalmente, a catástrofe propriamente dita. Dito em outras palavras, o ponto de ruptura se refere ao início da descontinuidade no qual a reprodução da morfologia urbana inicia um processo de decadência, no entanto, pouco perceptível na dimensão concreta. O ponto de dobra é quando crises de todas as ordens se instauram, tornando assim a descontinuidade da morfologia algo irreversível, o que significa, materialmente, a produção de novas formas com funções diferentes. Finalmente, o ponto de catástrofe se refere à efetivação de uma nova morfologia, mais complexa ou densa em relação à predecessora. Portanto, a expressão topológica da catástrofe tipo cúspide expõe uma morfogênese de duas pregas (dobras) acompanhadas de uma linha de conflito (instabilidade), Figura 1.

O que corresponderia a uma morfologia mais complexa? Só podemos responder isto a partir do estudo do espaço na sua dimensão morfológica (conjunto de unidades discretas). Afinal, se não houver uma diferença significativa, quantitativa e qualitativa, entre as camadas morfológicas então não faz sentido nem a noção de morfologia hierárquica estratificada nem a aplicação da Teoria das Catástrofes à produção do espaço. A resposta lógica que podemos dar a esta questão é a seguinte: as diferenças morfológicas do espaço não se deve a maior concentração de unidades formais discretas por área, mas sim pelo fato da maior concentração de capital por unidade de área, o que denominamos teoricamente na Geografia como um processo de valorização. 


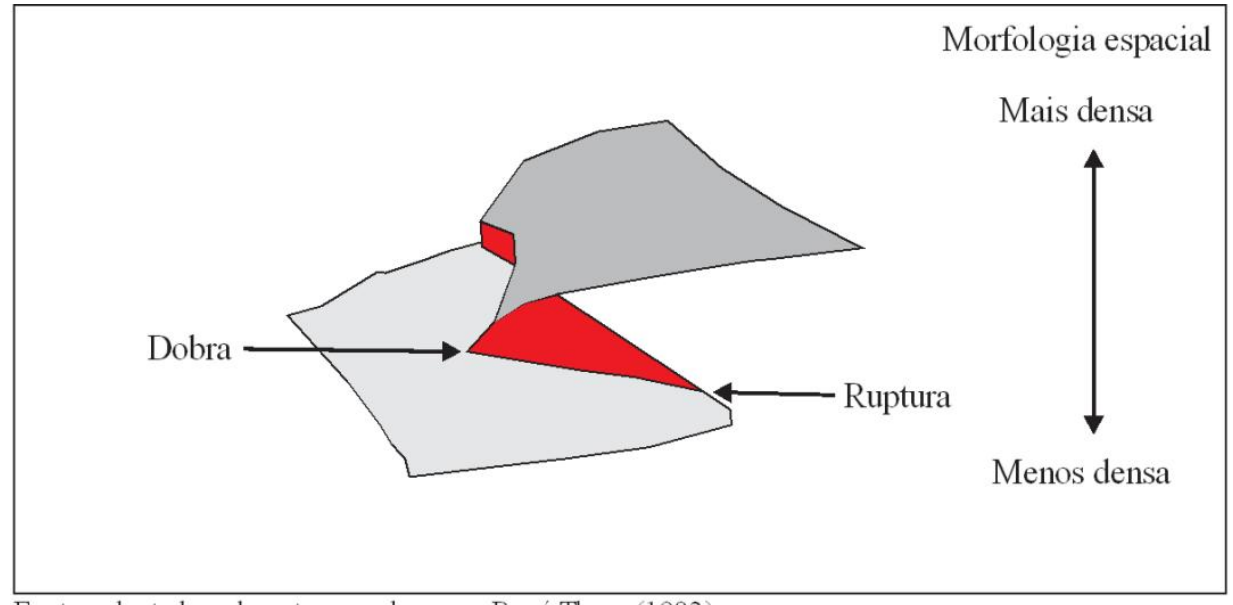

Fonte: adaptado pelo autor com base em René Thom (1983)

Figura 1: Morfogênese tipo cúspide.

Evidentemente que a topologia apresentada na Figura 1 se trata de um modelo. À parte as possíveis críticas a uma "modelização" do espaço, o que nos interessa é se aproximar de uma representação da produção do espaço urbano sob o enfoque aqui tratado, o que nos conduz a testar os modelos propostos por Thom e aditado por Lefebvre. Neste sentido, daremos prosseguimento à discussão sobre o processo de morfogênese enfocando o papel dos atratores. Logo, qual é a natureza de um atrator relativo à produção de uma morfologia hierárquica estratificada?

De acordo com Domingues (2004), as mudanças de base técnica (distribuição desigual de novas tecnologias) foram apontadas como sendo o cerne do processo de descontinuidades. Ora, a totalidade não pode ser reduzida a um aspecto, pois isto se trata de um fetiche, por isso Harvey (2018) destaca o equívoco das ciências sociais em privilegiar algum tipo de leitura unicausal de transformação social e, ao mesmo tempo, reafirma que Marx nunca fez uma leitura reducionista. Assim sendo, entendemos que o escopo causal é muito mais amplo e alcança mecanismos macrossociais associados ao processo de circulação do capital e suas expressões empíricas ao longo do tempo, traduzidas pelo regime de acumulação de valor em uma dada sociedade e seu rebatimento na morfologia espacial. Consequentemente, entendemos que os atratores que determinam o campo morfogenético de uma morfologia hierárquica estratificada espacial estão circunscritos no que entendemos ser a valorização na produção do espaço, integrada ao processo amplo de circulação do capital.

Antes de adentrarmos na discussão de valorização do espaço enquanto um processo em função de atratores valorativos, é preciso antes discutir o que consideramos ser o valor. Dentre os grandes debates da teoria marxista, sem dúvida, o do valor ocupa um lugar central. Esta centralidade advém do fato do valor ser uma categoria primordial da epistemologia materialista. Os estudiosos da obra de Marx chegam a elevar o valor a uma condição de lei social que explica o conjunto/estrutura das relações capitalistas, desde àquelas restritas a uma unidade produtiva até ao nível internacional. Portanto, temos aí o que fundamenta as relações da sociedade capitalista, mas como funciona esta lei?

O primeiro entendimento do valor advém do tempo de trabalho objetivado, logo, não se trata mais de um trabalho individual ou de corporação. $\mathrm{O}$ valor é uma expressão do capital adiantado empregado no ato da produção, o que engloba tanto o capital fixo (maquinaria/equipamentos/construções) quanto o capital variável (mão-de-obra) e o lucro médio. Por isso, Marx diz que "o valor das mercadorias está em razão direta com o tempo de trabalho invertido em sua produção" (MARX, 1984, p. 158), mas é bom lembrar que trabalho em Marx é "socialmente necessário". Contudo, enquanto mercadoria-produto, o processo de acumulação já está na circulação, logo, o valor passa a ser expresso como preço e sua troca é possível por dinheiro (equivalente geral).

Outro entendimento sobre o valor no processo de circulação de capital é de que ele assume distintas configurações e isto é crucial para a reflexão que ora empreendemos. Há, com efeito, o capital-monetário, o capital-produtivo e o capital-mercadoria (HARVEY, 2013). Estes momentos da circulação da capital significam o próprio estágio de desenvolvimento e complexidade no qual atingiu o capitalismo, portanto, para o escopo desta pesquisa, a produção do espaço urbano e o estudo morfológico espacial serão tratados enquanto produtos do capital ou capital-mercadoria. 
A produção do espaço, de uma maneira global, integrou-se à circulação do capital no decorrer do século $\mathrm{XX}$, esta é uma das teses lefebvrianas. Esta constatação produz consequências ao nível teórico porque interpõe necessariamente a superação de uma abordagem da organização do espaço. Não se trata mais da produção de uma casa, de um prédio, mas de conjuntos de unidades discretas. Desta forma, além do processo de homogeneização por equivalência da troca, o espaço também se fragmentou e se hierarquizou segundo a socio-lógica capitalista expressa em sua divisão de classes e seus mercados, contratos, leis etc.

Portanto, a produção de valor se realiza também na produção do espaço e segue o circuito acumulativo próprio da economia capitalista. David Harvey (2013) argumenta que o advento do capitalismo e a consolidação da circulação do capital (produção, realização, distribuição e consumo) não teria sido possível sem a acumulação de capital no espaço. A produção do espaço atende então a um dos problemas mais complexos do modo de produção capitalista, trata-se do excedente de capital e mão-de-obra. A transferência de capital e mão-de-obra funciona como um dos instrumentos regulatórios da circulação de capital (valor) sem, no entanto, resolver as irrupções de crise.

O valor ou melhor dito a gênese do valor é um elemento de compreensão teórica necessária para avançarmos na discussão do desdobramento relativo à valorização do espaço. Autores como Moraes e Costa (1984) são enfáticos em afirmar que todo o processo social, o que inclui a (re)produção do espaço, é determinado em última instância (estruturalmente) pela relação social entre trabalho e capital. Consequentemente, o reconhecimento de atribuição de valor ao espaço social corresponde a um momento necessário à caracterização de atratores envolvidos nos processos de morfogênese.

A valorização do espaço urbano é, portanto, uma derivação da inclusão do espaço social e, logo, de sua morfologia à reprodução do capital. Tal processo valorativo especifica dois processos imbricados e bastante complexos: um se trata da valorização do solo e outro da valorização do ambiente construído (capital fixado).

A valorização do solo, geralmente, é expressa pela renda fundiária proveniente da propriedade da terra. A teorização marxista sobre renda da terra deriva da teorização de renda fundiária agrária definida por David Ricardo ainda no século XVIII. Para simplificarmos a argumentação, observamos que Marx considera o solo (terra) um meio de produção não produtivo por não ser fruto do trabalho, isto no interior do sistema produtivo capitalista, por isso o alerta de Lefebvre em um ensaio sobre o tema, "a terra não tem nem valor nem preço" e "seu valor e preço vem das relações sociais" (1983, p. 13).

A partir da valorização da terra, a terra-matéria se transforma em terra-capital. As inversões (investimentos) de capital constituem o mecanismo pelo qual uma porção da superfície do planeta é valorizada tanto de forma transitória quanto permanente. Nesta última forma, Marx (2009, p. 797) nos explica que a terra-capital é capital fixo.

A transposição da teoria da renda solo para o meio urbano exige algumas derivações. Um dos estudos mais significativos sobre renda fundiária urbana se trata de Alain Lipietz (1974), no qual o autor adita a compreensão de renda incluindo a discussão de tributo fundiário (Estado) sobre uma parcela cadastral do solo urbano (unidades discretas) sujeita à penalidades, impostos, taxas, além da renda propriamente dita ligada aos proprietários. Segundo Lipietz (1974), no meio urbano, o papel dos agentes fundiários engloba uma prática político-jurídica interdependente da prática econômico/produtiva. Embora seja uma adição à teorização da renda da terra, isto não alterou o fundamento marxiano.

O tributo fundiário é uma expressão de implantação de infraestruturas urbanas realizadas pelo Estado. Neste sentido, tal qual terra-capital, temos no urbano o solo-capital pela incorporação de capital permanente ao solo. Estas infraestruturas dizem respeito aos sistemas de saneamento, iluminação, arruamento, pavimentação, serviços etc. Portanto, solo-capital possui valor e, consequentemente, preço.

Já a valorização do espaço propriamente dito se refere às condições materiais de reprodução do capital, ou seja, ao capital fixado ao solo enquanto formas espaciais, isto é, casas, edifícios, shoppings centers, hospitais, etc. (MORAES e COSTA, 1984). Estas formas (unidades discretas) constituem conjuntos que tanto são fruto da aplicação de capital quanto servem para reproduzi-lo. É por este processo de valorização do espaço que se constituiu, ano longo do século XX, um mercado e setor específicos para produzir e comercializar o espaço, sobretudo, o destinado à habitação.

Estes dois processos de valorização precipitam a acumulação de capital no espaço porque tanto o solo quanto o ambiente construído lastreiam a acumulação, mas efetivamente se tratam de capital adiantado porque o ciclo completo ou ciclo virtuoso de valorização envolve $\left(C-M-C^{\prime}\right)$. Logo, captar a expressão fenomênica de uma parte valorização do espaço, ou seja, (M) é crucial para o nosso intento de caracterização 
dos atratores de (re)produção morfológica do espaço. Por fim, entendemos ser esta a natureza dos atratores de valorização do espaço.

Contudo, como caracterizar os atratores da valorização do espaço urbano então? Entendemos que pelos preços médios indicadores de valor do metro quadrado de solo e, também, pelo preço médio de produção do metro quadrado de ambiente construído. Tais preços compõem as variáveis independentes da função de valorização. Há, contudo, uma ressalva: a ideia de valorização pressupõe uma apreensão do fenômeno em um período de tempo definido, logo, o que pretendemos é mensurar, a partir das funções doravante propostas, um momento do processo. Com efeito, as funções permitem captar momentos de valorização. Dito em termos matemáticos, propomos três funções polinomiais de primeiro grau para capturar o processo de valorização - uma relativa ao valor do solo, uma segunda que expressa o valor máximo e uma última relativa ao valor do espaço efetivamente produzido. Primeiramente, a função do valor do solo:

$\mathrm{Vs}=\mathrm{ax}+\mathrm{b}$

Onde: Vs = Valor do solo equivale a:

$\mathrm{a}=$ Valor Unitário Padrão (VUP)

$\mathrm{x}=$ Área de lote (metros quadrados)

$\mathrm{b}=$ Valor de partida VUP.

Sobre o valor do solo, isto é, do metro quadrado, a coleta desta variável terá como base ou constante o Valor Unitário do Padrão (VUP) ou equivalente, definido pela municipalidade de acordo com a planta de valores genéricos, anualmente publicada em diário oficial.

A partir desta função de valor do solo, derivamos para a função de valor máximo do espaço:

$\operatorname{VmaxE}=\mathrm{ax}+\mathrm{b}$

Onde:

VmaxE = Valor máximo do Espaço equivale a:

$\mathrm{a}=$ Área do lote*Índice de ocupação $(\mathrm{IO})^{*}$ Coeficiente de aproveitamento

$\mathrm{x}=$ Preço médio do metro quadrado construído

$\mathrm{b}=$ Valor do solo.

Por que é valor máximo do espaço por unidade-mercadoria? Isto decorre do valor provável que uma unidade-mercadoria do espaço pode alcançar em um determinado momento do processo de valorização. Por outro lado, o valor do espaço se realiza não exatamente conforme os interesses dos agentes envolvidos em sua produção, sobretudo, aqueles mais diretamente ligados ao mercado imobiliário. Neste sentido, propomos uma outra função matemática para expressar o valor efetivado do espaço por unidade-mercadoria. Tal função tem a seguinte expressão:

$\mathrm{VefeE}=\mathrm{ax}+\mathrm{b}$

Onde:

VefeE $=$ Valor efetivado do Espaço equivale a:

$\mathrm{a}=$ Área construída privativa total por unidade

$\mathrm{x}=$ Preço médio do metro quadrado construído

$\mathrm{c}=$ Valor do solo.

A diferença ou gap entre valor máximo e valor efetivado do espaço se constitui em campo rico de análises, uma possível é aquela do antivalor do espaço ou a antítese dialética do processo de valorização do espaço. (HARVEY, 2018).

A produção do espaço, em termos abstratos da circulação de capital, resulta em uma mercadoria negociável, mas com muitos riscos. Com efeito, a realização do valor desta mercadoria é crítica porque o tempo de giro completo do capital pode ser longo ou mesmo não se realizar, por isso, a necessidade da varredura do espaço (HARVEY, 2013) para acelerar a produção da mercadoria. Há ainda os ritmos de degradação e depreciação da unidade mercadoria que não precisam coincidir necessariamente. Ademais, o próprio Marx (1991) já deduzia que a medida do valor que não se realiza equivale ao seu contrário, isto é, o 
antivalor. Este se traduz abstratamente como sua desvalorização, e concretamente como depreciação e degradação.

Harvey (2018) correlaciona um antivalor a cada uma das três formas de valor do capital, isto é, a degradação ao valor de uso, a depreciação ao valor de troca e a desvalorização ao valor. $\mathrm{O}$ modo de realização do antivalor relativo ao espaço é bastante complexo porque envolve processos e temporalidades distintas. Há, contudo, uma reflexão sobre a desvalorização do espaço por unidade-mercadoria que podemos realizar. Trata-se da diferença entre a valorização máxima e a efetiva do espaço que indicaria um novo tipo de função, não mais linear, mas quadrática, mas isto requer uma aplicação para sua comprovação.

Por que é importante definir um antivalor do espaço? Talvez para indicar os momentos de descontinuidade do processo, a partir de sua crise de valor/valorização. Os atratores são forças como já dissemos, neste sentido, o antivalor corresponde, portanto, a um atrator negativo e dialético do valor. Dimensioná-lo, mesmo que potencialmente, ajuda-nos a refletir sobre o complexo processo de valorização/desvalorização do espaço materializado em sua morfologia.

Apesar de ainda ser uma primeira formulação indicadora do grau de não valorização de uma seção morfológica do espaço, a expectativa é torna-la uma medida efetiva. Por que? Porque o processo de valorização do capital se desdobra em dois ciclos, o primeiro é o de produção stricto sensu no qual D (capital constante + capital variável) se transforma em M (mercadoria, no caso, habitação-mercadoria), mas a outra parte é a realização do valor no mercado, ou seja, reconverter mercadoria em capital ampliado, ou M - D', aqui entram fatores exógenos de incerteza de negócio e tempo de realização, os quais são determinações concretas de realização do valor.

Damiani (2009) entende a relação dialética entre valor e antivalor como um indicador da reprodução crítica do urbano. Àqueles que se reproduzem abaixo do nível de equivalência exigida nos negócios relativos à (re)produção do espaço simplesmente são rechaçados e marginalizados. A cidade como um negócio não é para todos.

É neste contexto que agentes privados ou corporativos da produção do espaço urbano vão agir, consequentemente, conflitos pela apropriação do solo urbano vão passar a fazer parte da realidade políticosocial cotidiana a partir de práticas de competitivas. Muito embora até pareça que o Estado (enquanto agente) tenha a capacidade de dirigir conflitos pelo uso de instrumentos de regulação do uso do solo. Ou seja, o Estado, em suas diferentes instâncias e níveis de ação, reproduz os termos críticos da relação social de troca.

Por isso a acumulação de capital não se dá de maneira aleatória, pois, há o que denominamos de regime de acumulação de capitais. O regime de acumulação de capitais revela o padrão de realização da camada sociológica do capitalismo em uma formação social, logo, há uma regulação dos termos da acumulação e isto passa pela troca. Neste sentido, é preciso cotejar, dentro de um período de tempo histórico determinado, o desenvolvimento do regime de acumulação de capitais.

Em nosso estudo anterior, Araújo (2016), fizemos um estudo dos tipos de regime de acumulação de capitais e, com efeito, eles se consubstanciam em nossa formação social primeiramente como agrário e depois como urbano, sem haver exclusão do primeiro. Em termos bastante sucintos, a noção de regime de acumulação nasceu da teorização marxiana, e denota a regulação institucional (Estado) e demais agentes hegemônicos. (CHESNAIS, 2002; BOCCHI, 2000).

Enfim, a reflexão teórica até aqui empreendida procurou revelar a (re)produção do espaço a partir de uma perspectiva das estruturas reprodutivas as quais podem ser modelizadas por meio da Teoria das Catástrofes e da noção de morfologia estratificada lefebvriana.

\section{Considerações parciais}

Um dos maiores desafios a ser enfrentado é, sem dúvida, dimensionar empiricamente os atratores que produzem morfogênese de bifurcação a partir da solução matemática proposta. Neste sentido, a noção de morfologia hierárquica estratificada é uma chave preciosa neste caminho porque indica como os processos e agentes imbricados na (re)produção de uma morfologia estruturam níveis não só escalares, mas de complexidade social.

Há inúmeras possibilidades de aplicação do conceito de morfologia hierárquica estratifica na Geografia e, em especial, na Geografia urbana. Na realidade, o maior potencial que vislumbramos é desenvolver aplicações analíticas de morfogênese nos estudos geográficos. De fato, sabemos que o espaço é produzido, por quem é produzido, qual a sua finalidade, enfim, já sabemos muitas coisas, mas não sabemos ainda demonstrar por meio de correlação entre forma e conteúdo como um dado conjunto espacial se transforma. 
Para isto, deveríamos avançar, primeiramente, no sentido de uma aplicação matemática com o uso de funções diferenciais e integrais. E isto é possível?

A proposição de funções lastreadas pelo valor, mesmo que a partir de sua expressão fenomênica, isto é, o preço médio, é uma aposta que fazemos para expressar os momentos de ruptura e/ou continuidade de (re)produção espacial urbana. Não estamos certos ainda se o levantamento de dados de valorização, a ser feito a partir da aplicação de funções apesentadas aqui, permitirá confirmar a valorização do espaço. Quanto a formação de uma morfologia hierárquica estratificada nos termos aqui expostos as funções polinomiais não dão conta ainda porque são de primeiro grau.

Ainda sobre a valorização do espaço, há querelas que vão se manter por bastante tempo porque o valor é uma lei social de formação e reprodução da sociedade capitalista. Esta lei fundamenta toda a estratificação social, contudo, suas expressões fenomênicas acontecem sob a forma de preços porque o dinheiro se tornou equivalente geral de trocas, mas valor não é preço em um sentido stricto. Logo, sigamos com o debate.

Finalmente, a partir dessas considerações finais indicamos que os próximos passos serão a elaboração de dois artigos derivados deste - um primeiro que realiza as análises diacrônica e sincrônica da (re)produção espacial a partir de sua representação (topológica) enquanto morfologia hierárquica estratifica e, um outro subsequente, no qual aplicaremos as funções de valor como medida de valorização do espaço, a ser realizado a partir de um recorte empírico, o bairro do Jardim Armação, na cidade de Salvador/BA.

\section{Referências}

ARAÚJO, J. A. A Cidade Revisitada: modernização capitalista e reprodução da classe trabalhadora na periferia de Salvador. São Paulo: EDUSP, 2016.

BOCCHI, J. I.. Crises capitalista e a Escola Francesa da Regulação. Revista Pesquisa \& Debate, SP, volume 11, n. 1, p. 26-48, 2000.

CHESNAIS, F. A teoria do regime de acumulação financeirizado. Revista Economia e Sociedade, Campinas, v. 11, n. 1 (18), p. 1-44, jan./jun. 2002.

CORRÊA, R. L. Trajetórias geográficas. 2 ed. Rio de Janeiro: Bertrand Brasil, 2001.

DAMIANI, A. L. Reflexões sobre uma urbanização crítica a partir da metrópole de São Paulo. ANAIS ANPEGE. 2009. Disponível em: www.anpege.org.br/revista/ojs_2.2.2.

DOMINGUES, M. V. de la R. Dinâmica tecnológica: uma interpretação pela Teoria das Catástrofes. Revista Eletrônica do Mestrado em Educação Ambiental, volume especial, p. 84-109, out. 2004.

HARVEY, D. A loucura da razão econômica: Marx e o capital no século XXI. São Paulo: Boitempo, 2018.

HARVEY, D. Os limites do capital. São Paulo: Boitempo, 2013.

KOSMINSKY, E., ANDRADE, M. M. de. O Estado e as Classes Sociais. In: MARTINS, José de Souza (Org.). Henri Lefebvre e o retorno à dialética. São Paulo: HICITEC, 1996.

LEFEBVRE, H. Da Teoria das crises à Teoria das Catástrofes. Revista GEOUSP - Espaço e Tempo. São Paulo, no 25, pp. 128 - 152, 2009. Tradução de Anselmo ALFREDO, Carolina M. de PAULA, Thomas FICARELLI.

LEFEBVRE, H. A revolução urbana. Belo Horizonte: Editora UFMG, 2004.

LEFEBVRE, H. La production de l'espace. $4^{\text {ème }}$ ed. Paris: Anthropos, 2000. 485 p.

LEFEBVRE, H. La Teoría Marxista-Leninista de la renta de la Tierra. In: La Renta da la Tierra: 5 ensayos. Ciudad de Mexico: Ed. Tiauialli, 1983.

LEFEBVRE, H. De l'État - 4. Les contradictions de l'État moderne. Paris: Union Générale d’Éditions, 1978. 
LEFEBVRE, H. Au-delà du structuralisme. Paris: Éditions Anthropos, 1971.

LEFEBVRE, H. Vers le Cybernanthrope - contre les Technocrates. Paris : Denoël/Gonthier, 1971.

LEFEBVRE, H. O fim da História. Lisboa: Publicações Dom Quixote, 1971.

LIPIETZ, A. Le Tribut Foncier Urbain. Paris: F. Maspéro, 1974.

LOPES, I. C. Semiótica e morfodinâmica: em busca de vicissitudes. Seminários Teóricos Interdisciplinares do SEMIOTEC - I STIS. ANAIS do I STIS. Belo Horizonte: UFMG, nov./2012.

LUKÁCS, G. História e consciência de classe: estudos sobre a dialética marxista. São Paulo: Martins Fontes, 2003.

MARX, K. El capital: critica de la economia política. Livro terceiro, vol. VIII, El processo global de la produccíon capitalista. Madri: Siglo XXI, 2009.

MARX, K. O Capital: crítica da economia política. 5 ed. Livro terceiro, vol. I, o processo global de produção capitalista. São Paulo: Difel, 1991.

MARX, K. O Capital: crítica da economia política. 9 ed. Livro primeiro, vol. I, o processo de produção do capital. São Paulo: Difel, 1984.

MARSAULT, X. Contribution de la Théorie de la Catastrophe à l'étude et à l'analyse des images.1998. Tèse de Doctorat. Ecole Nationale des Travaux Public de l'Etat. VaulxenValin. 200 p.

MORAES, A. C. R., COSTA, W. M. da. A valorização do espaço. São Paulo: HUCITEC, 1984.

OSEKI, J. H. O único e o homogêneo na produção do espaço. In: MARTINS, Jose de Souza. Henri Lefebvre e o retorno à dialética. São Paulo: HUCITEC, 1996.

SANTOS, M. A natureza do espaço: técnica e tempo, razão e emoção. 2 ed. São Paulo: 1997, HUCITE.

STAVENHAGEN, R. Classes sociais e estratificação social. In: MARTINS, José de Souza \& FOFACCHIA, M. M. Sociologia e sociedade: leituras de introdução à Sociologia. Rio de Janeiro: Livros Técnicos e Científicos, 1980.

THOM, R. Structural Stability and morphogenesis: on outiline of a general theory of models. Washington (D.C.): Westview Press, 1989.

THOM, R. Paraboles et catástrophes: entretiens sur les mathématiques, la science et la philosophie réalisés par Giulio Giorello et Simona Morini. Paris: Flammarion, 1983.

THOM, R. Modèles Mathématiques de la Morphogènese. Paris: Christian Bourgois éditeur, 1980. 